This item was submitted to Loughborough's Research Repository by the author.

Items in Figshare are protected by copyright, with all rights reserved, unless otherwise indicated.

\title{
HADRIAN: fitting trials by digital human modelling
}

PLEASE CITE THE PUBLISHED VERSION

http://www.springerlink.com/content/t5w88588k6q04455/

\section{PUBLISHER}

(C) Springer Verlag

\section{VERSION}

AM (Accepted Manuscript)

\section{LICENCE}

CC BY-NC-ND 4.0

\section{REPOSITORY RECORD}

Case, Keith, Russell Marshall, Dan Hogberg, Steve Summerskill, Diane E. Gyi, and Ruth Sims. 2019. "HADRIAN: Fitting Trials by Digital Human Modelling". figshare. https://hdl.handle.net/2134/10643. 
This item was submitted to Loughborough's Institutional Repository (https://dspace.lboro.ac.uk/) by the author and is made available under the following Creative Commons Licence conditions.

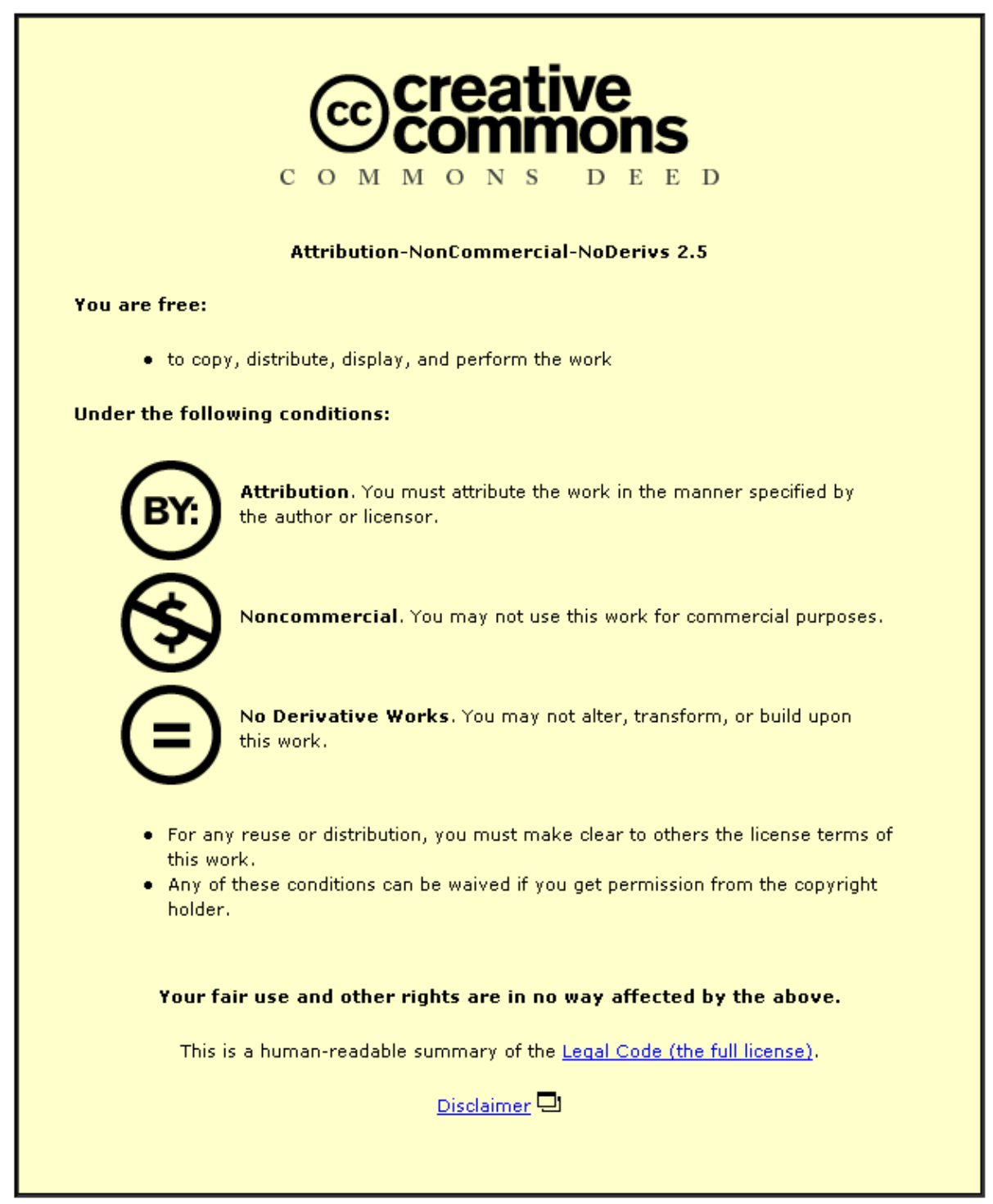

For the full text of this licence, please go to: http://creativecommons.org/licenses/by-nc-nd/2.5/ 


\title{
HADRIAN: Fitting Trials by Digital Human Modelling
}

\author{
Keith Case ${ }^{1,4}$, Russell Marshall ${ }^{2}$, Dan Hogberg ${ }^{4}$, Steve Summerskill ${ }^{2}$, \\ Diane Gyi ${ }^{3}$ and Ruth Sims ${ }^{2}$ \\ ${ }^{1}$ Mechanical and Manufacturing Engineering, ${ }^{2}$ Department of Design and Technology, ${ }^{3}$ \\ Department of Human Sciences, Loughborough University, UK \\ ${ }^{4}$ The School of Technology and Society, University of Skövde, Sweden \\ \{k.case, r.marshall, s.j.summerskill2, d.e.gyi, r.sims\}@lboro.ac.uk dan.hogberg@his.se
}

\begin{abstract}
Anthropometric data are often described in terms of percentiles and too often digital human models are synthesised from such data using a single percentile value for all body dimensions. The poor correlation between body dimensions means that products may be evaluated against models of humans that do not exist. Alternative digital approaches try to minimise this difficulty using pre-defined families of manikins to represent human diversity, whereas in the real world carefully selected real people take part in 'fitting trials'. HADRIAN is a digital human modeling system which uses discrete data sets for individuals rather than statistical populations. A task description language is used to execute the evaluative capabilities of the underlying SAMMIE human modelling system as though a 'real' fitting trial was being conducted. The approach is described with a focus on the elderly and disabled and their potential exclusion from public transport systems.
\end{abstract}

Keywords: Keywords: Digital Human Modelling, User Trials, SAMMIE, HADRIAN

\section{$1 \quad$ Introduction}

The collection and application of anthropometric data within digital human modelling systems raises many questions. Often the data will have been collected for direct use in a particular design application and may not meet the more generic needs of human modelling systems. There is a consequent need for some transformation to for example convert the external body dimensions normally collected in anthropometric surveys into the internal joint-to-joint dimensions that form the basis of most models. However, perhaps the most significant problem arises from the use of a 'percentile' approach that is in conflict with the multivariate nature of anthropometric data. Fifth and ninety-fifth percentile models are commonly used in the belief that this will 'accommodate' an appropriate proportion of the user population. This, however, assumes that good correlation exists between body measures whereas it has long been understood that correlation between some body measures can be extremely weak. Hertzberg [1], in a large survey of over 4000 Air Force personnel found no examples of men who fell within the 30 percent central (average) range on all of a series of ten 
measurements. This is to say that the man who is average in all dimensions, and thus an 'average' man, just does not exist, because the correlation between different dimensions is not sufficiently high. In the human modelling world handling this problem is frequently left as an issue for the user of modelling systems to deal with raising the question as to whether all users are sufficiently aware of the difficulties to deal with them satisfactorily. Alternative approaches have constructed 'families' which try to encompass the multivariance within a limited number of models such as the 17 manikins of A-CADRE [2] or the 45 manikins of the RAMSIS Typology [3]. Figure 1 shows the A-CADRE female family and figure 2 shows 6 members of the RAMSIS typology constructed according to a method defined by Speyer[4]. Hogberg [5] gives a graphic comparison of the A-CADRE family and the full RAMSIS family (figure 3).

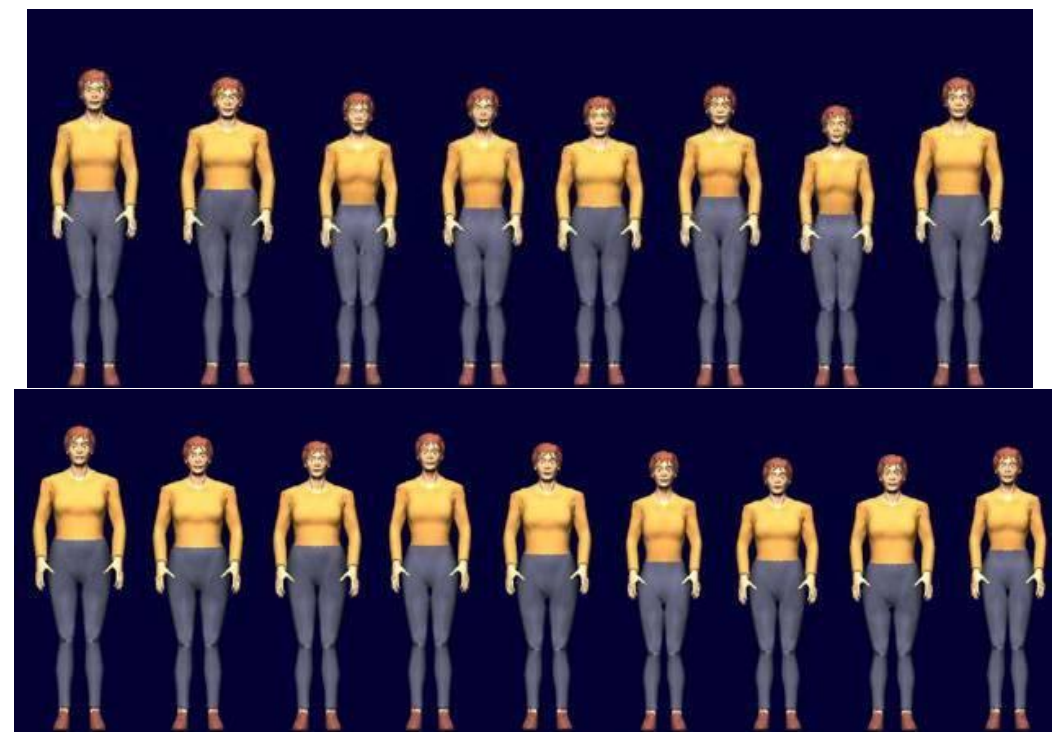

Fig. 1. Female A-CADRE family [2] constructed in RAMSIS

In real 'fitting trials' a panel of people selected to be representative of the eventual users interact with the product or a prototype. To carry out the equivalent activity in digital human modelling it is necessary to have anthropometric (and other) data available in individual sets (rather than population statistics such as percentiles) and there needs to be some way of describing the interactions with the product (a task description). Both of these important aspects are provided by the HADRIAN system. 


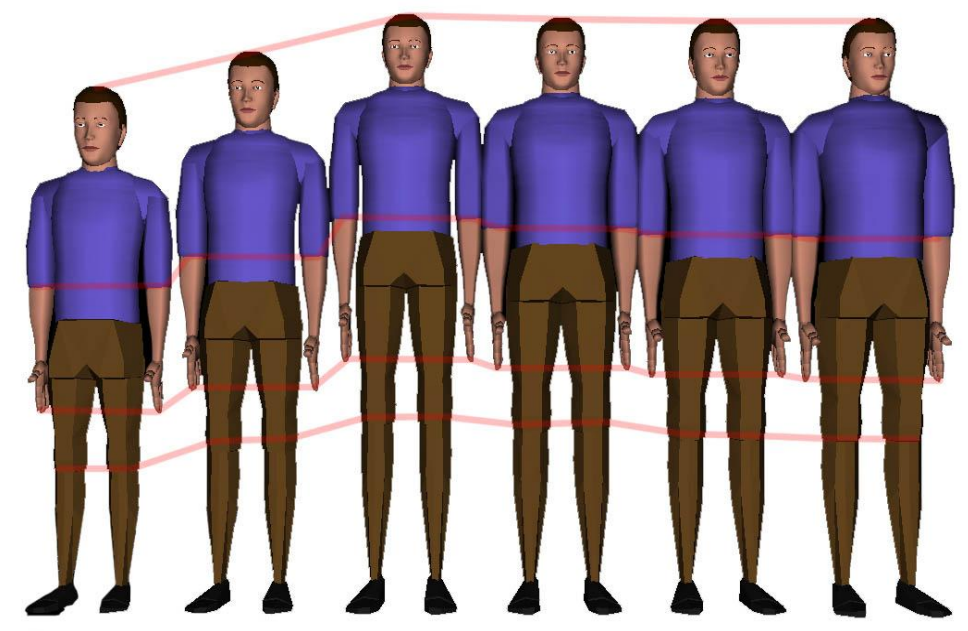

Fig. 2. Some male members of the RAMSIS typology constructed in Jack [6]

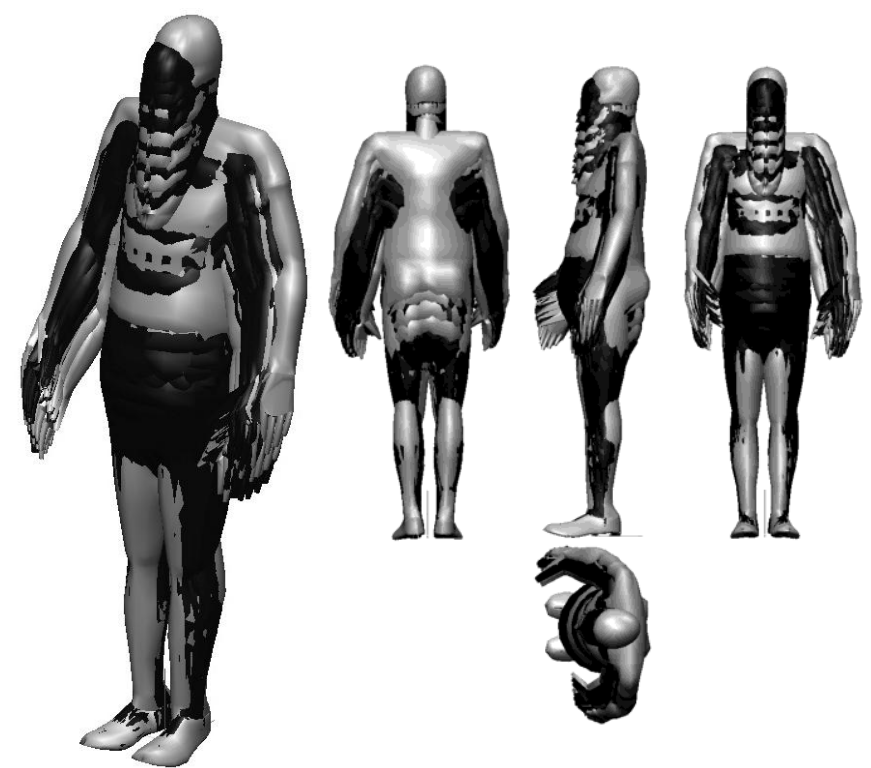

Fig. 3. Skin compositions of RAMSIS Typology (black) and A-CADRE (grey) male manikin families (Hogberg, [5])

\section{Data Collection}

Important aspects of diversity arise from the users of products being older than the general population or through having some disabilities and these have been reflected 
in our data collection. This emphasis on older and disabled people comes from earlier work within the EQUAL (Extending Quality Life) programme [7] which was a 'design for all' activity that recognised the needs and opportunities of an aging population, and similar considerations but focussed on transport in current work concerned with Sustainable Urban Environments (SUE)[8]. Details of the data collection can be found in [9] and some indication of the variety of data available is shown in figure 4 (from [10]). The data collected includes anthropometry, joint constraints, reach and mobility which is presented to the designer/ergonomist as sets relating to individuals together with additional information such as video clips which illustrate particular problems that an individual might have due to a disability. This data and the form of its presentation has considerable value in its own right but becomes more potent when associated with a task-driven human model as described next. The diversity of the members of the database is illustrated in figure 5 .

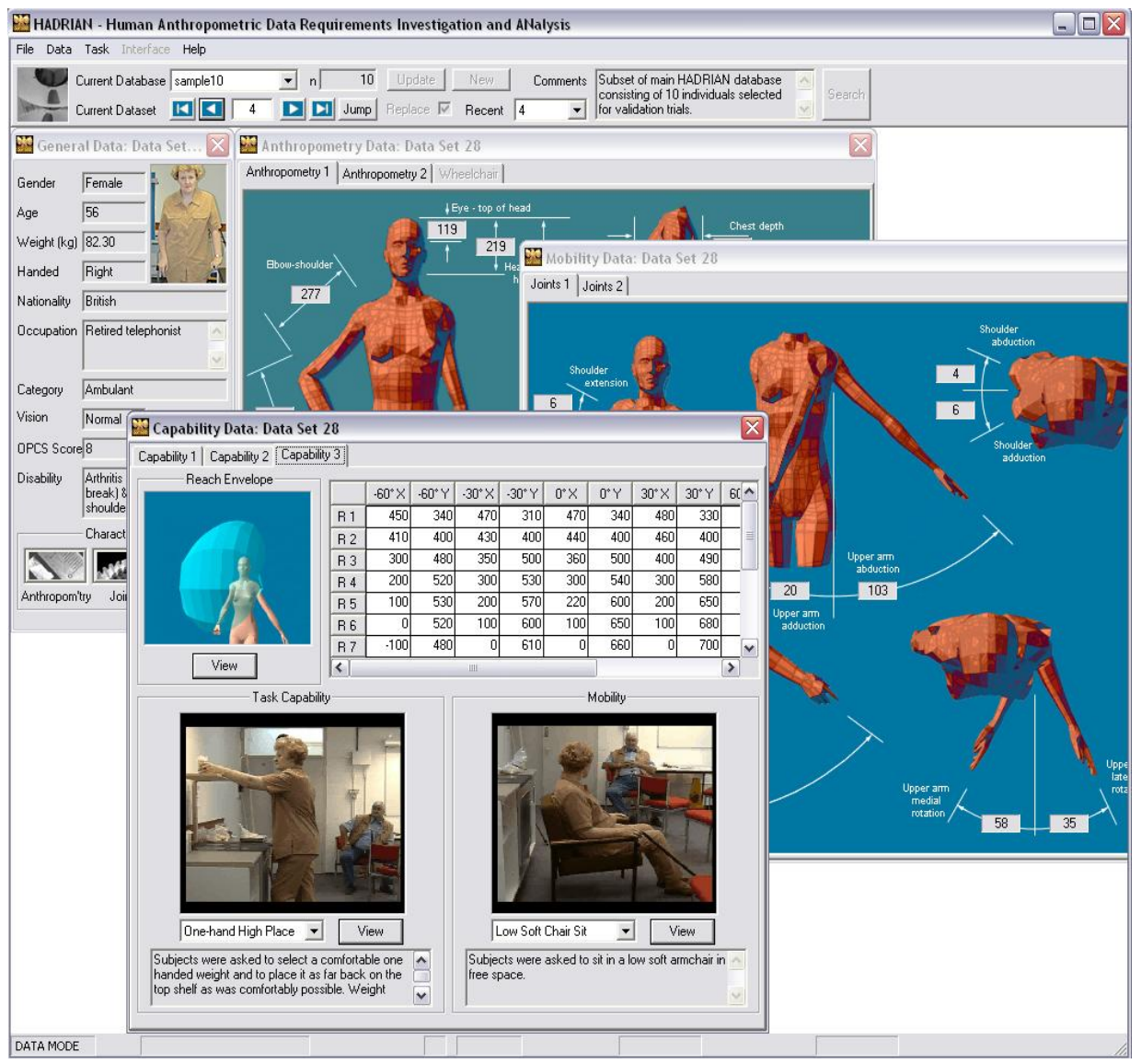

Fig. 4. Examples of various windows for a specific individual in the HADRIAN database 


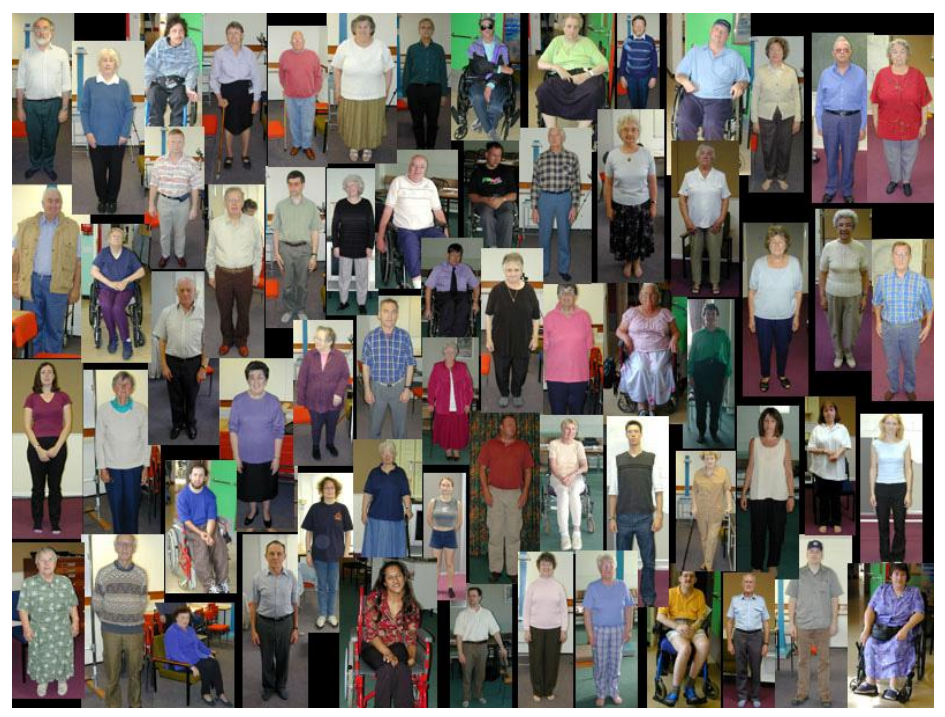

Fig. 5. Members of the HADRIAN database

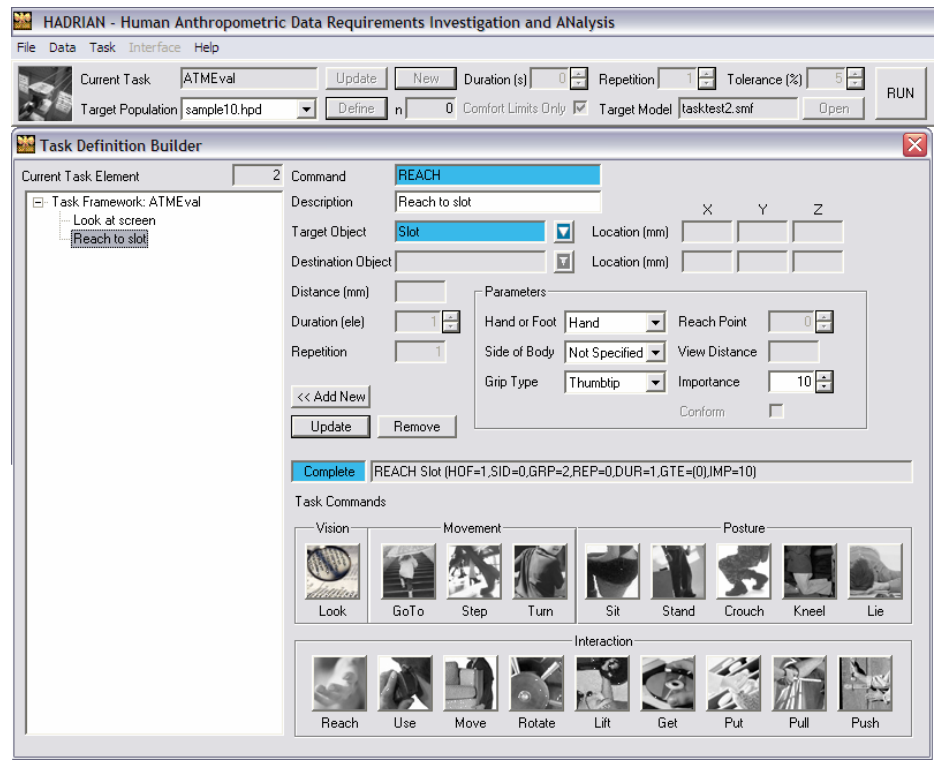

Fig. 6. Constructing a Task Analysis in HADRIAN

\section{Task Description Language}

HADRIAN contains the database of individuals described above plus a task description method for driving the underlying and long-established SAMMIE (System for Aiding Man-Machine Evaluation) system [11]. The task and its evaluation criteria 
are defined using a simple task description language (figure 6) and the subsequent analysis uses this to create and drive a human model to evaluate their capability in performing the task. The figure shows a small part of the task of obtaining money from an Automatic Teller Machine (ATM) where the first two elements are 'look at screen' and 'reach to slot'. The complete task is evaluated for each individual in the database and a degree of intelligence is applied to the analysis - for example the reach to the card slot will be performed by the individual's preferred hand as handedness is an item in the database.

On completion of the task analysis the percentage accommodated will be presented. This is the percentage of the individuals in our database that have been predicted to complete the whole task successfully. Should any individual be unable to complete the task then they will be identified and the situation causing the difficulty will be displayed (e.g. figure 7) together with a suggestion for improvement.

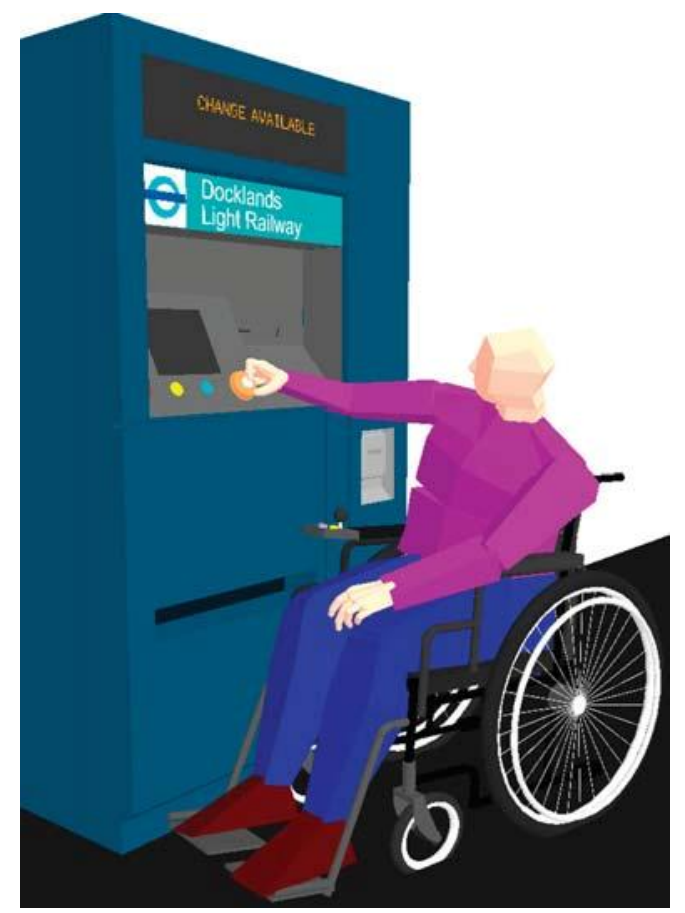

Fig. 7. Best attempt to reach card slot

\section{$4 \quad$ Accessibility and User Needs in Transport}

Current research using HADRIAN is considering accessibility aspects of public transport systems. The work is focussed on the creation of a journey planner as the 'journey' expresses the need for individuals to complete extended tasks with failure in any one aspect making the entire task impossible. For example, a journey from home to a hospital followed by a visit to the pharmacy and a return home could involve 
walking, buses and trains with interchanges between the modes. Two test-bed sites in Camden (central London) and Hertfordshire (rural towns) are being used to identify a number of relevant journeys from which we can collect data. The journeys will be based on observation and real world experience from people and will include all of the accessible design elements that the individuals will have to deal with on those journeys. Potential barriers faced by the people who make these journeys are being identified (figure 8). These barriers may take many forms including physical, cognitive and emotional. The physical barriers (e.g. kerbs, lifts, escalators and street furniture) are the most easily assessed using human modelling techniques, but our data collection activity has included aspects of the cognitive (e.g. understanding of signage and timetables) and emotional (e.g. security concerns) characteristics of individuals. Many of these barriers may arise with in the course of making a journey and if any one prevents the user from achieving a relatively small part of the overall task it may well prevent the journey from being possible.

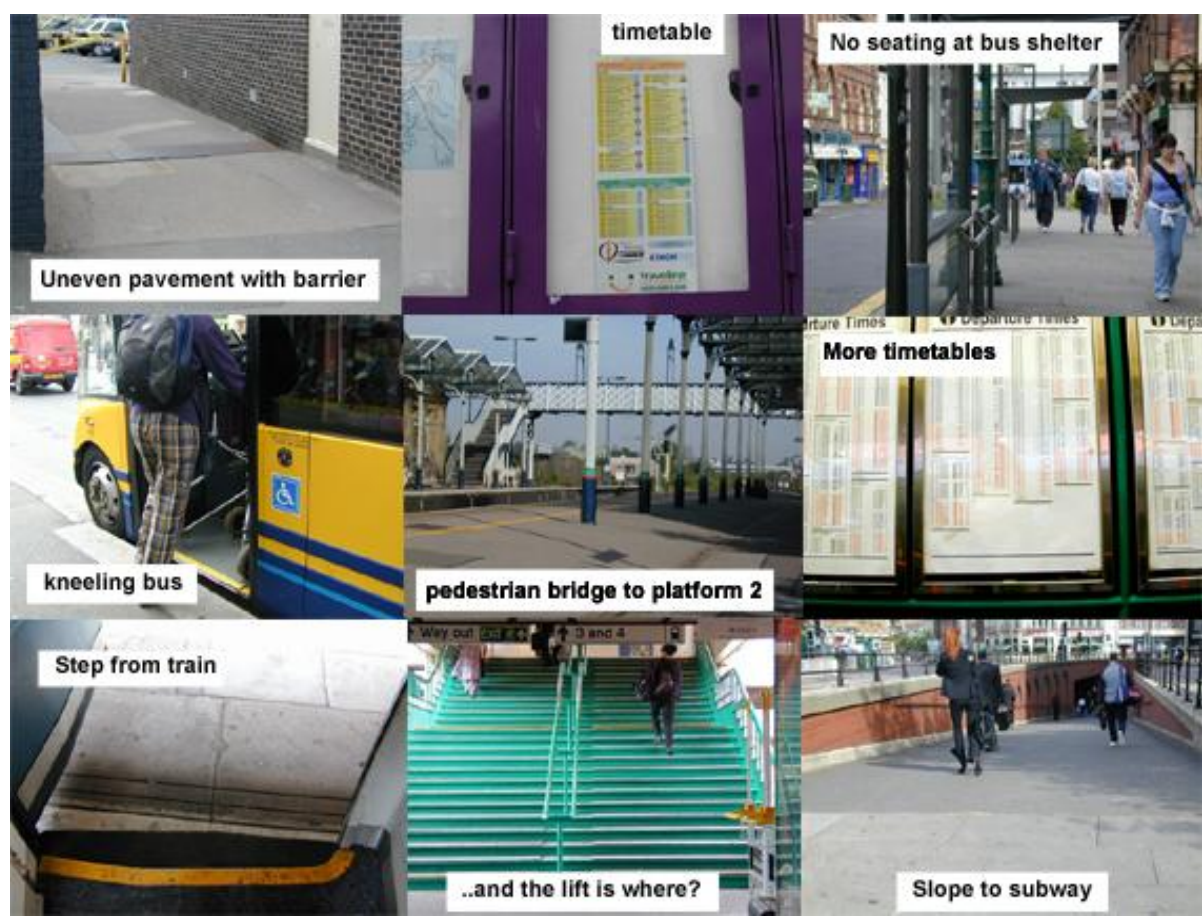

Fig. 8. Potential barriers faced during a typical journey.

\section{Conclusions}

The multivariate nature of human data gives rise to considerable difficulty in the proliferation of digital human modeling techniques beyond the specialist activity into the general world of product design. The design of evaluations and the interpretation of results requires considerable knowledge and a professional ergonomist. This paper 
has described an approach that is intended to alleviate this problem to a certain extent by replicating the fitting trials of the real world by the equivalent in the virtual world of digital human modelling. The use of a task-based approach is also considered to be essential and HADRIAN's task description capabilities allow the modeling system to be used as an automated evaluation tool. It also allows for the consideration of issues beyond the physical aspects of anthropometry so that some consideration can be given to the cognitive and emotional issues faced by the individuals in the database.

\section{References}

1. Hertzberg, H.T.E. Dynamic Anthropometry of Working Positions. Human Factors Vol . 2, No 3. August 1960.

2. Bittner, A. C. A-CADRE: Advanced family of manikins for workstation design. XIVth congress of IEA and 44th meeting of HFES, San Diego. 774-777, 2000.

3. Bubb, H., Engstler, F., Fritzsche, F., Mergl, C., Sabbah, O., Schaefer, P. and Zacher, I. The development of RAMSIS in past and future as an example for the cooperation between industry and university. Int. J. of Human Factors Modelling and Simulation 1(1): 140-157, 2006.

4. Speyer, H.On the definition and generation of optimal test samples for design problems, Kaiserslautern Human Solutions GmbH, 1996.

5. Hogberg, D. Ergonomics Integration and User Diversity in Product Design, PhD Thesis, Loughborough University, 2005.

6. Badler, N.I., Phillips, C.B. and Webber, B.L.Simulating Humans: Computer Graphics, Animation and Control, Oxford University Press, 1993.

7. Extending QUAlity Life. http://www.extra.rdg.ac.uk/equal/

8. Sustainable Urban Environments (SUE). http://www.epsrc.ac.uk/ResearchFunding/Programmes/PES/SUE/default.htm

9. Gyi, D.E., Sims, R.E., Porter, J.M., Marshall, R and Case, K.Representing Older and Disabled People in Virtual Users Trials: Data Collection Methods, Applied Ergonomics, 35, 443-451, 2004.

10.Porter, J.M., Marshall, R., Sims, R.E., Gyi, D.E. and Case, K. Hadrian gets streetwise. Proceedings of the IEA2006, International Ergonomics Association Triennial Congress, Maastricht, The Netherlands, July 2006.

11.Case, K., Porter, J.M. and Bonney, M.C.SAMMIE: A Man and Workplace Modelling System. In: Computer-Aided Ergonomics, Eds. Karwowski, W., Genaidy, A. \& Asfour, S.S., 31-56, Taylor \& Francis Ltd, 1990. 